\title{
La memoria histórica, sus lugares y el uso político en Navarra"
}

\author{
Memoria historikoa, memoria-tokiak eta horien erabilera politikoa \\ Nafarroan
}

Historical memory, its places and political use in Navarra

\author{
Juan-Cruz Alli Aranguren \\ Universidad Pública de Navarra \\ juancruzalli@unavarra.es \\ Recibido / Noiz jaso den: 30/09/2020 \\ Aceptado / Noiz onartu den: 24/11/2020
}

\section{Resumen}

En el debate político reciente se ha introducido la "memoria histórica» como objeto del mismo y de los intereses partidistas, invocando la historia como instrumento político. Para recuperar su significado se ha realizado este estudio de conceptos desde la visión científica, al margen del debate político. En la primera parte se estudia el concepto doctrinal de la memoria histórica y su presencia en los genéricamente llamados lugares de memoria, materiales o inmateriales, en que cristaliza su significado. En la segunda se conceptualiza el uso político de la memoria por agentes, medios y fines, que se realiza por los grupos dominantes o minoritarios, consagrando concepciones historicistas, tradicionalistas y reaccionarias, al margen del rigor científico histórico. Todo ello se aplica a la realidad y uso en el territorio de Navarra, concluyendo que es práctica habitual de todas las ideologías el uso político de la memoria y de sus lugares.

\section{Palabras clave}

Memoria histórica; uso político; Navarra.

\section{Sumario}

1. LA MEMORIA HISTÓRICA. 1.1. Concepto. 1.2. Lugar es de memor ia. 2. EL USO POLÍTICO DE LA HISTORIA. 2.1. Concepto. 2.2. Agentes, medios y fines. 3. VIGENCIA EN NAVARRA. 3.1. Los "Fueros". 3.2. Conmemoraciones y lugares. 4. CONCLusiones. BiBliografíA.

* Este artículo es producto de la memoria investigadora «El carlismo de Franco. De Rodezno a Carlos VIII», presentada en la Universidad Nacional de Educación a Distancia, bajo la dirección del Prof. Dr. D. Juan Avilés Farré. 
Laburpena. Azkenaldiko eztabaida politikoan, eztabaidetako objektu gisa eta alderdikeriaz erabili dute "memoria historikoa», tresna politiko moduan aipatu baitute historia. Memoria historikoaren esanahia berreskuratzeko, ikuspegi zientifikotik egin da kontzeptuen ikerketa hau, eztabaida politikotik kanpo. Lehenbiziko partean, memoria historikoaren kontzeptu doktrinala ikertzen da, eta nolako presentzia duen kontzeptu horren esanahia gauzatzen den lekuetan, hau $\mathrm{da}$, oro har memoria-leku material eta immaterial deitzen zaienetan. Bigarren partean, berriz, gizarteko zenbait eragilek eta komunikabidek helburu jakin batzuekin memoria politikoki nola erabili duten kontzeptualizatzen da, hau da, talde gailenek eta minoritarioek kontzepzio historizistak, tradizionalistak eta erreakzionarioak eman dizkiotela zehaztasun zientifikorik eta historikorik gabe. Hori guztia Nafarroako errealitateari eta erabilerari aplikatu zaio, eta ondorioztatu da ideologia guztiek egin dutela memoriaren eta memorialekuen erabilera politikoa.

Gako hitzak. Memoria historikoa; erabilera politikoa; Nafarroa.

\begin{abstract}
In the recent political debate, "historical memory" has been introduced as a subject and of partisan interests, invoking history as a political instrument. To recover its meaning, this study of concepts has been carried out from the scientific point of view, outside the political debate. In the first part, the doctrinal concept of historical memory and its presence in the generically called 'places of memory', material or immaterial, in which a meaning crystallizes is studied. In the second, the political use of memory is conceptualized from its practice, stakeholders, means and ends that are pursued by dominant or minority groups, establishing historicist, traditionalist and reactionary conceptions regardless of historical scientific rigor. All this applies to the reality and uses in the territory of Navarra, with reference to the places and events in which they occurred, with the attributed meaning.
\end{abstract}

Keywords. Historical memory; political use; Navarra.

El presente trabajo busca conocer y formar criterio sobre realidades historiográficas y sociales de nuestro tiempo, vividas intensamente por la sociedad democrática española, particularmente por la navarra.

\section{La memoria histórica}

\subsection{Concepto}

La memoria es la «facultad síquica por medio de la cual se retiene y recuerda el pasado». Se estima que la memoria es la «evocación o rememoración», «como presente del pasado»:

La memoria rinde presente el pasado y la historia da razón de la memoria. [...] es la vida, se traslada con los vivos y, en ese sentido, está en evolución permanente, abierta a la dialéctica del recuerdo y de la amnesia, inconsciente de sus deformaciones sucesivas. [...] La historia, por el contrario, es la reconstrucción siempre problemática e incompleta de lo que ya no existe ${ }^{1}$.

\footnotetext{
1 Sánchez Prieto, 2005, p. 11.
} 
Nora definió la memoria histórica como «el recuerdo o conjunto de recuerdos, conscientes o no, de una experiencia vivida y/o mitificada por una colectividad viviente, de cuya identidad el pasado forma parte inteǵrante» ${ }^{2}$.

La memoria histórica de una colectividad es historia, y como esta, sujeta siempre a revisión y actualización de su conocimiento. El «régimen de historicidad» articula pasado, presente y futuro dándoles sentido entre el «espacio de experiencia»y el «horizonte de expectativa»(Koselleck, 1993), ya que no existe una sin la otra. Hartog delimitó el periodo de la historicidad moderna entre el conflicto de regímenes que se produjo con la Revolución Francesa de 1789, «conflicto entre dos regímenes de historicidad», y la caída del muro de Berlín de 1989 y el fin del régimen comunista. A partir de ese hecho existe el tiempo moderno, presente o "presentismo», caracterizado en la sociedad capitalista por la aceleración de la vida, la imagen y las representaciones. Explicó las «hipótesis de rompimiento» que produjo el acontecimiento como representación del fin de un régimen político que había sido hegemónico ${ }^{3}$.

Halbwachs diferenció la memoria de la historia; aquella es una «corriente continua de pensamiento [...] no retiene nada del pasado que no esté viviente o sea capaz de vivir en la conciencia del grupo que la mantiene, reconociéndole una función reconstructiva del pasado» ${ }^{4}$. En su concepción, el pasado se reconstruye en el presente, que se mantiene en los marcos sociales con una función social: «El pasado, mitificado, es utilizado para justificar las representaciones sociales del presente [...], es efecto del presente, como lo es del pasado». Por eso, «hay tantas memorias como grupos, es por naturaleza múltiple y desmultiplicada, colectiva, plural e individualizada». Es «multiforme y se inscribe en la multiplicidad de tiempos sociales y espacios diferenciados de los que se apropian los grupos», resultando «vulnerable a todas las utilizaciones y manipulaciones».

$\mathrm{Su}$ interpretación de la memoria sobre la base social fue matizada por Assmann con la presencia de lo cultural. Diferenció entre las memorias episódica o de experiencia y semántica o de aprendizaje, individual y social o colectiva, dentro de esta entre la comunicativa y la cultural. La comunicativa se produce oralmente en marcos sociales de espacio-tiempo generacionales, mientras que la cultural vincula la memoria y las identidades, trayendo «al presente algo lejano y ajeno, que no tiene lugar en la vida diaria y por lo tanto debe ser evocado en intervalos regulares con el fin de preservar un contexto amenazado por la desinteǵración y el olvido», que se exterioriza y objetiva en formas simbólicas, representativas y estables. Abarca «lo originario, lo excluido, lo descartado y en

2 Citado por Lavabre, 2006, p. 40.

3 Hartog, 2007, pp. 130-132.

4 Halbwachs, 2004, p. 54. 
contraste con la memoria vinculante y colectiva, lo no instrumentalizable, lo herético, lo subversivo, lo separado». Es un "giro ontológico de la tradición [que] puede sintetizarse con la fórmula 'el ser que puede ser recordado es texto' [...] se constituye apelando a una comunicación previa». El miedo a la pérdida del grupo o de su identidad «trae al presente algo lejano y ajeno [...], debe ser invocado en intervalos regulares, con el fin de preservar un contenido amenazado por la desintegración y el olvido» ${ }^{5}$. Puede conducir a defenderlos con comportamientos esencialistas-historicistas, cuando no agresivos frente a los agentes de la trasformación, en un «nosotros» contra los «otros», los «amigos» contra los «enemigos» del grupo. En esta dialéctica, se entiende el papel decisivo de la cultura mediática para configurar la memoria, la identidad y su proyección colectiva.

Las generaciones reciben la memoria colectiva como «el relato vivo de los primeros actores y espectadores que se desarrolla dentro de un 'marco espacial' y se construye con gran peso de los poderes político, mediático y económico para su reconfiguración o recuperación, que, si les conviene, siempre será interesada» ${ }^{6}$.

Expuso Mudrovic que «toda historia contemporánea es una forma de memoria, aunque se reconozca en la historia una instancia de crítica del recuerdo», cuestionando la objetividad histórica, porque la memoria es selectiva: «La memoria colectiva no consiste en la transmisión de un conjunto de hechos acerca del pasado, sino que es, ante todo, un código semántico que opera como contexto en el proceso de recuperar los recuerdos individuales». Planteó la dificultad de alcanzar la «neutralidad valorativa», que «funciona como locus sociohistórico de auto atendimiento ético-político desde donde se reconstruye el fenómeno y no como garantía incuestionada de una presunta reconstrucción objetiva» ${ }^{7}$.

La historia está siempre sujeta a revisión y actualización de su conocimiento. Nuevos estudios y aportaciones conducen a reinterpretar el pasado, porque la historia es «un esfuerzo encaminado a conocer mejor algo en movimiento», un «continuo»y un «cambio perpetuo», que «pone en tela de juicio hasta la razón de nuestros trabajos». El tiempo presente es un tiempo en cambio y transformación, por lo que historiarlo exige «una historización del desarrollo», superando la idea «de que sólo aquellas realidades sociales de las que existe una perspectiva temporal que permite captarlas en sus detalles y consecuencias finales pueden ser objeto de la Historia» ${ }^{\text {. }}$.

Los «mercaderes de la memoria» utilizan la memoria colectiva para su servicio ideológico, mítico o de clase. Hacerlo constituye «una de las máximas pre-

5 Assmann, 2008, pp. 47, 15 y 34 .

6 Halbwachs, 2004, pp. 80, 88 y 144.

7 Mudroveic, 2005, pp. 17, 118 y 129; Ramos, 1989, p. 71.

8 Aróstegui, 1998, p. 42. 
ocupaciones de las clases, de los grupos, de los individuos que han dominado y dominan las sociedades históricas. Los olvidos y los silencios de la historia son reveladores de estos mecanismos de manipulación de la memoria colectiva» ${ }^{9}$. Porque la memoria trata de «salvar el pasado sólo para servir al presente y al futuro, $[\ldots]$ ha constituido un hito importante en la lucha por el poder conducida por las fuerzas sociales» ${ }^{10}$.

La memoria desaparece o hiberna por hechos traumáticos, sobre los que se produce el olvido, el silencio consciente, la evasión o la ocultación de sus huellas y manifestaciones. Estos comportamientos pueden variar con el cambio histórico y cultural, resurgiendo cuando desaparecen las causas represivas que los impedían, adquiriendo relevancia histórica, incluso dando lugara a conductas que tienen como contrapunto la «obsesión» por el pasado. En ese momento la memoria inicia un camino contrario al anterior, tratando de recuperar los espacios, las celebraciones y demás hechos pasados, deliberadamente olvidados u ocultados, que tratan de reconstruir una nueva memoria, a veces tan manipulada como la anterior, pero en sentido inverso.

\subsection{Lugares de memoria}

La memoria histórica se cristaliza en lugares en sentido material, simbólico y funcional, cuya razón de ser es «detener el tiempo, bloquear el trabajo del olvido» ${ }^{11}$. Según Nora, autor del concepto creado al servicio del Estado-nación, «el lugar de la memoria es una noción abstracta, puramente simbólica, destinada a separar la dimensión memorial de los objetos que pueden ser materiales, pero también y sobre todo inmateriales» ${ }^{12}$. Persiguen «fijar un estado de cosas, inmortalizar la muerte, materializar lo inmaterial para [...] encerrar el máximo de sentidos en el mínimo de signos». Consideró tales a «toda unidad significativa, de orden material o ideal, que la voluntad de los hombres o el trabajo del tiempo convirtieron en elemento simbólico del patrimonio memorial de una comunidad cualquiera». Son materiales concretos o abstractos intelectualmente construidos, que «escapan al olvido y a los que una colectividad les da afectos y emociones». Sobre ellos se apoya una memoria individual o colectiva asumida socialmente.

Advirtió Nora del riesgo de la «saturación», del «abuso patrimonial» y de la «tiranía de la memoria», al utilizarse para «compensar el desarraigamiento histó-

\footnotetext{
9 Le Goff, 1991, p. 134.

${ }^{10}$ Le Goff, 1991, p. 183.

11 Yerushalmi, 1998, p. 18.

${ }^{12}$ Leoné Puncel, 1999b, pp. 339-348; 2005, p. 23.
} 
rico de lo social y la angustia del porvenir por la valoración del pasado, que no era hasta entonces visto como tal».

Los lugares constituyen «una exploración selectiva y erudita de los puntos de cristalización» de la cultura e identidad, un inventario de la «topología de la historiografía [...] que respondiera más que a la historia clásica, a las necesidades científicas y cívicas de nuestro tiempo». Nora usó una metodología «muy tradicional», que suponía volver al positivismo, pero «es al mismo tiempo muy nueva [...] una historia que ha entrado en su edad epistemológica». Sirven para reconstruir el pasado por los actores sociales como «conjunto de representaciones y actitudes respecto del pasado, propias de una colectividad y variables en el tiempo» ${ }^{13}$.

Suelen ser objeto de topolatría y topofilia, por «el lazo afectivo entre las personas y el lugar o el ambiente circundante. Difuso como concepto, vívido y concreto en cuanto experiencia personal» ${ }^{14}$, convertidos en símbolos y objeto de culto cívico e, incluso, religioso.

\section{El uso político de la Historia}

Observó Koselleck que «el futuro histórico no se puede derivar por completo a partir del pasado histórico» ${ }^{15}$, y que la historia ha de ser «permanentemente reescrita» ${ }^{16}$. Sin embargo, existe el riesgo de utilizar el pasado para justificar proyectos y actitudes del presente, como si estuviesen determinadas por aquél. Políticos e historiadores tratarán de compatibilizar el compromiso intelectual y la militancia para legitimar un proyecto o para ponerlo al servicio de los poderes dominantes en una sociedad, por medio de los «usos públicos de la historia» ${ }^{17}$.

Es propio de la política convertir la historia en relato para el debate político y la lucha social, «como espacio de experiencia y medio de reflexión de la unidad política o social a la que se aspira», porque «siempre se está atado a la situación de conocimiento» ${ }^{18}$. La valoración del buen o mal uso está en función del rigor historiográfico, generalmente ausente del partidismo.

Habermas y los historiadores alemanes plantearon en 1986-1987 en la «Controversia Goldhagen» el debate sobre el tratamiento del periodo nacionalsocialista, la complicidad social, el revisionismo negacionista de los crímenes nazis y la

\footnotetext{
${ }_{13}$ Nora, 1984 , p. 226 ; 2008, pp. 18-21, 32-34 y 111; 1998, p. 33.

14 Tuan, 2007, p. 13.

15 Koselleck, 1993, p. 341.

${ }^{16}$ Koselleck, 2004, pp. 27-45.

17 Pasamar Alzuría, 2003, pp. 221-248.

18 Supelano-Gross, 2010, p. 59.
} 
«quiebra de la civilización» ${ }^{19}$. El aspecto doǵmático se amplió al «usufructo que intereses de muy diversa entidad y naturaleza han venido practicando de la historia». De todos ellos, el político «es el más determinante, pues permea todos los demás y, en sus formas extremas, es el que degrada a la historia, transformándola en una historia meramente instrumental, sin más razón que su utilidad para ser usada» ${ }^{20}$.

\subsection{Concepto}

El uso político es uno de los modos del «uso público de la historia», que es la representación política y cultural que de la historia realizan los medios de comunicación de masas, las artes, la literatura, la escuela ${ }^{21}$, los museos, los monumentos, los espacios urbanos y las instituciones reguladas o no (asociaciones culturales, partidos, grupos religiosos, étnicos o culturales, etc.).

Gallerano definió el uso público de la historia de un modo extrínseco, como el «que se desarrolla fuera de los lugares destinados a la investigación científica, en sentido estricto, a la historia de los historiadores». Invocó la definición extrínseca, «amplia y débil», de Habermas, distinguiendo entre los ámbitos científicos y los mass-media, endurecida por «objetivos político-pedagóǵicos explícitos: construir el consenso alrededor de algunos valores decisivos para la convivencia civil», oponiendo el uso público y la actividad científica. Concluyó que «es necesario un uso público de la historia consciente y crítico, capaz de poner en cuestión la opacidad y la eternidad del pasado para rescatarlo de la tiranía del presente» ${ }^{22}$.

\subsection{Agentes, medios y fines}

El uso público de la historia se realiza por los agentes de la política, la memorialística $^{23}$, las conmemoraciones, la «industria de la nostalgia» y los medios de comunicación. Constituye un «uso periférico», leǵitimador o desleǵitimador, de la ideología, las posiciones y decisiones, enaltecimiento del grupo y critica del adversario. Apoyado en el conocimiento construido o en la interpretación de hechos seleccionados por la historiografía, se utiliza para justificar políticamente

\footnotetext{
${ }^{19}$ Habermas, 1989, pp. 104-116.

${ }^{20}$ Kocka, 2002, pp. 29-31.

${ }^{21}$ Hartoǵ y Revel, 2001, p. 16.

${ }^{22}$ Gallerano, 1995, pp. 17-32; 2007, pp. 87 y 97.

${ }_{23}$ Traverso, 2007, pp. 14-16.
} 
la bandera ideológica como «una charca donde se pescan ejemplos más o menos casuales, útiles para la polémica de última hora» ${ }^{24}$.

Quienes practican el uso político de la Historia pretenden recobrar la memoria del pasado para reconstruirla con el propósito de utilizarla en el presente: «Rememorar el pasado es un acto del presente, hecho por hombres del presente, y que afecta al sistema social del presente ${ }^{25}$. Tras todo ello está la búsqueda de la adhesión de la sociedad y el mantenimiento del control sobre las relaciones de poder, utilizando la historia para conseguir objetivos presentes: «Articular históricamente el pasado no significa conocerlo 'tal como verdaderamente fue'. Significa apoderarse de un recuerdo tal como éste relumbra en un instante de peligro». Tanto como «encender en el pasado la chispa de la esperanza es un don que sólo se encuentra en aquel historiador que está compenetrado con esto: tampoco los muertos estarán a salvo del enemigo, si éste vence. Y este enemigo no ha cesado de vencer» ${ }^{26}$.

Para ello se tiende a la «simplificación de la imagen pasada, a la creación de estereotipos y a la formulación de conclusiones definitivas e incontrovertibles». La llamada «historia viva» «no respeta ni la integridad del recuerdo ni del acontecimiento histórico», sino que «trata el pasado como si fuera algo inmediatamente accesible al presente», «borra la diferencia entre el hecho y la ficción» y «da autenticidad a sus invenciones produciendo una variedad de efectos-realidad» ${ }^{27}$.

El uso político maneja el lenguaje y los conceptos sin insertarlos ni en el contexto, ni con el significado en que se produjeron, ni en su horizonte conceptual, ya que en ellos se aprehenden los acontecimientos que se valoran. Los desfigura en su significado, confundiendo la palabra y el concepto. Es lo contrario del trabajo del historiador, para quien «reconducir los conceptos a la época significa insertarlos en el proceso histórico que los haya generado [...], sobre todo, en su horizonte conceptual global, y en su principio organizativo: sin ello, los conceptos son desfigurados inevitablemente en su significado» ${ }^{28}$.

El uso político de la historia es muy utilizado, aunque no exclusivamente, por los discursos románticos, nacionalistas, fundamentalistas, esencialistas e historicistas. Basan el relato en su concepción de la verdad esencial y en un pasado en el que buscan el presente, para lo que los esencialistas utilizan el historicismo. El paradiǵma esencialista implica un retorno idealista a los orígenes, convertido en una filosofía que prioriza la esencia sobre la existencia, identificando un ente eterno, invariable e inalterable, sus cualidades y diferencias. Persigue construir

\footnotetext{
${ }^{24}$ Gallerano, 2007, p. 88.

${ }_{25}$ Wallerstein, 1999, p. 15.

${ }^{26}$ Benjamín, 2005a y 2005b.

${ }_{27}$ Samuel, 1999, p. 197.

${ }^{28}$ Koselleck, 2009, pp. 6-10.
} 
un relato del pasado para el presente y el futuro, aquel cuanto más remoto es menos aprehensible y más fácilmente imaginado. Convierte la historia de una comunidad «en un sistema de creencias, con sus dogmas de fe y sus axiomas» ${ }^{29}$.

En estas prácticas se invocan conceptos políticos y categónías organizativas modernas, que tienen su propia historicidad, dándoles viǵencia universal objetiva, sustancializando constructos propios de la ciencia política contemporánea que se aplican al pasado. Con estos conceptos tratan de formar la mentalidad y condicionar el entendimiento y la contemporaneidad ${ }^{30}$.

$\mathrm{El}$ «pasado presentista» o «presentismo» se invoca en el presente para resolver urǵencias dialécticas, buscar soluciones a las nuevas realidades o, simplemente, para rechazar el tiempo presente, sustituyéndolo por la idealización de la pasada Arcadia feliz. Constituye una concepción que es reaccionaria, como mucho tradicionalista, por medio de un pasado «omnipresente en su abundancia de evocaciones» ${ }^{31}$.

Este comportamiento lleva a la «invención de la tradición», que es «esencialmente un proceso de formalización y ritualización, caracterizado por la referencia al pasado, aunque sólo sea al imponer la repetición» de prácticas, que «implica automáticamente continuidad con el pasado. En este sentido se produce la intervención de las élites que controlan los aparatos de poder ${ }^{32}$, intentando conectarse con un pasado histórico que les sea adecuado» ${ }^{33}$.

Cuando se observan las políticas de la memoria y los usos públicos de la historia, hay que preguntarse con Burke: «¿Quién quiere que alguien recuerde, por qué y para qué?, ¿a quién pertenece y realiza la versión?» ${ }^{34}$.

Los medios para el uso político de la historia se utilizan por los grupos y las ideologías dominantes, porque «apoderarse de la memoria y del olvido es una de las máximas preocupaciones de las clases, de los grupos, de los individuos que han dominado y dominan las sociedades históricas» ${ }^{35}$. Persigue «moldear los pensamientos y las conductas de la mayoría»: «La aceptación de los modelos y de los mensajes propuestos se opera a través de adecuaciones, rodeos y en ocasiones resistencias que manifiestan la singularidad de cada apropiación ${ }^{36}$.

Pero también se practican por las minorías para lo contrario, incluida la transgresión o la utilización de un discurso victimista, que justifique la resistencia y la

\footnotetext{
${ }^{29}$ Nancy, 2000, p. 118.

${ }^{30}$ Duso, 1998 , pp. 54 y 56.

${ }^{31}$ Lowenthal, 1998 , pp. 5 y 6.

${ }^{32}$ Hobsbawm, 1992, pp. 18-19, 55, 89 y ss.

${ }^{33}$ Hobsbawm, 2002, pp. 8 y 10.

${ }^{34}$ Burke, 2011, p. 81.

${ }^{35}$ Le Goff, 1991, p. 134.

${ }^{36}$ Chartier, 1995, p. 12.
} 
lucha activa de las comunidades menores, marginadas o perseguidas. Sirve para enfrentarse a la mayoría, a la globalización y al multiculturalismo que alteran y cambian sus paradigmas nacionales, culturales o políticos.

Es habitual en el debate político y social hacer un uso político de la historia, construyendo metarrelatos a partir de un dogma esencial, de axiomas, de premisas innegables, de una narración verdadera, de objetivos irrenunciables, de hechos indiscutibles e irrefutables y de la realidad objetiva, incluso en posiciones encontradas. Se invoca la memoria construida del pasado, que a veces no coincide con la histórica, en función de los problemas, necesidades y debates del presente, practicando el historicismo, las conmemoraciones, la topolatría, la tradición, el presentismo, solos o combinados sobre los mismos hechos y lugares, pero con significados distintos.

Todas las prácticas señaladas y la tradición inventada, «hasta donde les es posible, usan la historia como legitimadora de la acción y cimiento de la cohesión del ǵrupo» ${ }^{37}$, o inspiradora de proyectos político-sociales. Constituyen claves legitimadoras del ser de la comunidad política. Una vez comprobado su éxito, se mantiene el discurso arcaizante e historicista, sin tomar en consideración los cambios que se hayan podido producir en la sociedad, porque la llamada al sentimiento creado se ha demostrado rentable política y electoralmente.

Tales comportamientos y el uso descontextualizado e interesado de la historia es propio de cuantos la han manipulado al servicio de intereses políticos, sociales o económicos. Todos buscan el control, la legitimación de su orden, valores e instituciones, sacralizando su visión y proyección imaginaria del pasado para justificar el presente. Álvarez-Junco (2003, p. 66) afirmó que en todas las épocas la percepción de la realidad social está mediatizada, y «considerar el pasado como una realidad que puede captarse de forma objetiva aplicándole métodos de investiǵación racional no es sino una ingenua y presuntuosa creencia decimonónica».

\section{Vigencia en Navarra}

La sociedad navarra es propicia a vivir del pasado, practicando un tipo de historicismo que para Nancy «presupone que la historia de hecho siempre está comenzada, limitándose a continuar» ${ }^{38}$. Utiliza un historicismo doǵmático y determinista aplicado al presente. De ahí la búsqueda obsesiva de la historia bajo la «sensación de estar siendo arrastrada hacia el futuro por fuerzas irresistibles» ${ }^{39}$,

\footnotetext{
${ }^{37}$ Hobsbawm, 1992, p. 19.

${ }^{38}$ Nancy, 2000, p. 112.

${ }^{39}$ Popper, 1957, p. 160.
} 
que rechaza el pluralismo y condiciona las decisiones del presente. Practica un consumo permanente de historia en los planteamientos ideológicos, en los conflictos y en la «obsesión conmemorativa» ${ }^{40}$. Se sacralizan los signos identificadores y los «lugares de memoria» de una historicidad medieval presentista, como realiza Martín Duque respecto a Navarra ${ }^{41}$. Se fomenta la simbología ${ }^{42}$ y la «invención de la tradición». En Navarra se ha practicado el uso político por todos, de todos los modos y con todos los medios, con mayor intensidad por los nacionalistas y por el nacionalismo banal, como medio para mantener y fomentar la memoria social ${ }^{43}$.

En torno a la historia política e institucional de Navarra se han construido lugares de memoria, inmateriales y materiales, tanto en el momento de producirse los hechos como posteriormente para darles una versión ideologizada e interesada. Me limitaré a algunos supuestos a título de ejemplo.

\subsection{Los «Fueros»}

Los Fueros, como concepto vagoo e indeterminado, significante sin significado comúnmente admitido, sirven para crear mitos y debates nominalistas, metafísicos y retóricos, en alǵunos casos francamente bizantinos. Desde su polisemia se invocan como el referente principal de la identidad navarra, encuadrando la historia, el Derecho, las instituciones, la relación con la monarquía hispánica, la distribución del poder, la capacidad de autogobierno, pasados y presentes. Demasiados significantes para un término tan impreciso, que exige matizarlo en su alcance temporal y material.

Se convirtieron históricamente en un signo de identidad difusa de un territorio, de una colectividad política, de sus instituciones, de la sociedad, y en una abstracción, lugar de memoria, con distinto alcance para cada sujeto, tiempo y lugar.

Sobre ellos se ha producido el debate intelectual y político de los esencialistas-historicistas de cualquier signo, que, buscando dar contenido suficiente al concepto de identidad, convierten el sentimiento y la decisión diferenciadoras en ontología. Esta actitud se enfrenta al relativismo del pluralismo de la libertad democrática, que es posthistórica e inicia una nueva historia, demostrando que

\footnotetext{
${ }^{40}$ Nora, 2008, p. 195.

${ }^{41}$ Martín Duque, 1996.

42 Billiǵ, 1995.

${ }^{43}$ Hobsbawm, 2002, p. 8.
} 
donde hay historia no hay esencia, y si hay esencia no es historia, salvo que se haya podido abstraer la esencia y hacer su historia.

Desde la perspectiva esencialista, los Fueros han sido sublimados en los intentos de buscar la identidad como «encarnación» del «ser» y la «esencia» de un ente suprapersonal, suprasocial y suprahistórico que es «Navarra» ${ }^{44}$. Pero sin sacar la conclusión de que, si los fueros son identidad esencial, su variación en su contexto temporal, material, histórico y social implicaría, necesariamente, la de la esencia, que ya no sería eterna ni inmutable. Para no asumirlo, les dan un valor abstracto y ahistórico, metafísico, de verdad inconmovible ${ }^{45}$.

Esa concepción es radicalmente opuesta a la consideración de una comunidad política de personas con derechos, voluntad política y capacidad de decidir sobre su presente y futuro. Los Fueros como el ser y la identidad, prejuzgadas conforme a la ideología, configuran lugares de memoria o interpretan los existentes en función del prejuicio en una manifestación del uso político de la historia. El esfuerzo por llegar al «ser» nunca se ha logrado, pero ha servido para construir metarrelatos y mitos convertidos en lugares de memoria.

Existe la tradición de hacer un uso político de la historia: en las crisis forales del siǵlo XVIII; en el XIX, en el enfrentamiento entre el Antiguo Réǵimen y el liberalismo en el fin del orden institucional del Antiguo Régímen, sobre el encuadramiento institucional dentro de la monarquía y si el contenido de los Fueros era pacto o concesión real ${ }^{46}$. Constituyeron ejemplos notorios del uso político de los conceptos y categorías del pasado, fuera de su contexto, cultura y significado, los intentos de las instituciones del Reino de Navarra de asimilar las propias del Antiguo Régimen con el constitucionalismo de Cádiz. Con todos ellos quisieron demostrar que la «constitución histórica» de la monarquía medieval, limitada, templada y pactista, era el mismo modelo liberal al recoger los principios de separación de poderes, limitación del poder real y garantía de los derechos ${ }^{47}$.

En las luchas decimonónicas entre el absolutismo y el liberalismo, los Fueros fueron utilizados como medio para desactivar el conflicto con la promesa de mantenerlos. Sobre las leyes de 1839 y 1841, aprobadas por unas Cortes liberales, se mantuvieron las posturas contrarias de los carlistas y el debate doctrinario sobre si la última era o no pactada.

El conflicto se ideologizó en el siǵlo xx, en el debate sobre el Estatuto vasco durante la II República, planteándose la identidad vasca de Navarra. Reapareció en la Transición entre los conservadores navarristas y los nacionalistas, entre la

\footnotetext{
${ }^{44}$ Sánchez Prieto, 2002, pp. 11-40; 2013.

45 Sánchez Prieto, 1998.

46 Sánchez Prieto y Nieva, 2002.

${ }^{47}$ Alli, 1998, 2011, 2012, 2014.
} 
derecha y la izquierda defensora de la identidad vasca y la integración en una entidad política, entrando a formar parte de la lucha de clases $^{48}$.

Con la demanda de «reintegración foral plena», el carlismo, el nacionalismo y la Diputación franquista intentaron demostrar que su navarrismo llevaba a recuperar el Reino anterior al constitucionalismo y a las leyes de 1839 y 1841, sobre las que la corporación se defendía frente a la democracia y la Constitución ${ }^{49}$.

La disposición adicional primera de la Constitución de 1978, que invoca los «derechos históricos de los territorios forales», ha sido el punto de apoyo para reconstruir la «memoria foral» del pacto con la Corona y del derecho originario a la autodeterminación. Ha dado una nueva legitimación constitucional al hecho foral histórico, elevando su relato y teorización anteriores al reconocimiento constitucional y al rango de leyes orgánicas, que los incorporan y desarrollan en el Estatuto de autonomía de la Comunidad Autónoma Vasca y en La ley orgánica de reintegración y amejoramiento de Navarra (LORAFNA). En sus debates se reconstruyeron las representaciones y apropiaciones de la historia, su memoria y utilización.

En la LORAFNA se acumularon en su preámbulo los elementos historicistas identificadores y diferenciadores, con referencias a los momentos de la conquista de Navarra, a la construcción nacional, y a la sustitución del Reino por una provincia foral en el siǵlo XIX, según l a concepción esencial ista del navar rismo de Pradera y Esparza, recuperado y adaptado por Del Burgo. La insistencia en la soberanía originaria, en la bilateralidad y el carácter «paccionado» de la ley de 1841 , se relacionan con el pactismo medieval entre una comunidad soberana y su monarca, aplicando al momento categorías políticas contemporáneas. Constituye un modo de nacionalismo basado en una identidad esencial, aunque se manifieste de forma «banal» respecto a los elementos que lo integran (historia, identidad, lengua, símbolos, signos $\left.{ }^{50}\right)$. Sirven para perpetuar la identidad colectiva, cuya intensidad de uso puede llevar al nacionalismo manifiesto, confirmando que es «más sencillo reconocer el nacionalismo en los otros que en ellos mismos» ${ }^{51}$.

\subsection{Conmemoraciones y lugáares}

Establecido el marco institucional, no se abandonó el uso político de la historia con las conmemoraciones, los símbolos y los discursos electorales y partidistas. Siempre realizados por todos los defensores de tramas identitarias, con una visión maniquea del relato.

\footnotetext{
48 Leoné, 2005.

${ }^{49}$ Baraibar Etxeberria, 2004, 2005, 2006.

${ }^{50}$ Martín Duque, 1996.

${ }^{51}$ Billiǵ, 2014, p. 38; 1998, pp. 37-57.
} 
Sirvan de ejemplo de obsesión conmemorativa del navarrismo en el Gobierno de Navarra en el 2012 lo siguiente. Celebró episodios dispersos en el tiempo y de distinto contenido: el centenario de la batalla de las Navas de Tolosa (1212) y la conquista de Navarra (1512), como demostración de españolidad, omitiendo las Cortes de 1812, referencia del fin del Antiguo Régimen y del Reino. Se completó con los treinta años del Amejoramiento del Fuero de 1982. Para esta trama identitaria y esencialista eran más relevantes los acontecimientos de hacía siǵlos, que el de ciento setenta años, en que se estableció el régímen constitucional en España. En ese totum revolutum era evidente que, aislados de su contexto, se utilizaban para justificar y dar una apariencia histórica al discurso ideológico navarrista-españolista.

Con el mismo carácter de uso político de la historia se invocaron por el nacionalismo vasco episodios seleccionados de la historia de Navarra para explicar el objetivo político y construir la ideología, en la sesión constitutiva del Parlamento Vasco de 31 de marzo de 1980. Su presidente estableció la continuidad histórica del pasado en el presente, buscando en la historia de Navarra la legitimación del proyecto político nacionalista. Recordó a cuantos «han hecho que hoy esto sea posible» y a los lugares de memoria: Orreaǵa (Roncesvalles, 778), Amayur

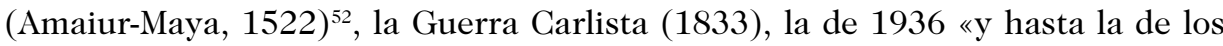
que han luchado por la libertad durante los últimos cuarenta años [ETA]» ${ }^{53}$.

Esta combinación del uso político de la historia con los lugares de memoria, aplicando románticamente hechos históricos medievales a un proyecto nacional creado por el integrismo conservador a finales del siǵlo XIX, reconstruido por la izquierda radical en la segunda mitad del xx, ha permitido a la izquierda abertzale construir los antecedentes del «conflicto vasco» sobre las revueltas del Bajo Imperio romano (siǵlos III a v), las luchas con los visigodos y la derrota de Carlomaǵno en Roncesvalles (778) ${ }^{54}$. En la celebración conmemorativa de 1978, la calificó de la «más grande victoria militar vasca en tiempos históricos», salvadora del «pueblo vasco» y «origen del reino de Euskal Herria», que representaba los valores de «la libertad frente al invasor imperialista, la defensa de la personalidad autóctona vasca frente a la imposición del modo de ser feudal y latino, y lo que es más decisivo todavía: Navarra como adalid de todos sus hermanos euskaldunes» ${ }^{55}$.

Este discurso incluyó la conquista de Navarra en 1512, los conflictos sociales internos y las guerras civiles del siǵlo XIX, haciendo de los carlistas los héroes de la

\footnotetext{
52 Sánchez-Prieto y Olabarri, 1985.

53 Parlamento Vasco, Diario de sesiones, 1, 31 de marzo de 1980, p. 40.

${ }^{54}$ Se trata de construir un imaginario y un relato patriótico al servicio de un proyecto político en un ejemplo del uso político de la historia. Hobsbawn, 1997, pp. 71-72.

${ }^{55}$ Iriarte, 2000, pp. 664-673.
} 
independencia vasea, prescindiendo de su defensa del orden absolutista y el integrismo religioso frente al liberalismo y durante la Guerra Civil ${ }^{56}$. El conflicto de ETA era el último episodio de la permanente «guerra imaǵinaria ${ }^{57}$, a favor de la independencia de Euskadi todavía inconclusa. Con esta explicación histórica de un pueblo siempre víctima, se trató de justificar y difuminar que los conflictos son internos, formando parte de una larǵa historia de guerracivilismo en conflictos sangrientos y casi permanentes entre linajes (oñacinos y gamboinos), rivalidades ente reinos y dinastías (castellanos de las provincias contra navarros), ideologías y regímenes políticos (carlistas y liberales), posturas sobre la foralidad de liberales y carlistas (internamente, integristas y transaccionistas, reintegracionistas y cuarentayunistas), antirrepublicanos y republicanos en la guerra civil, tradicionalistas-carlistas-carlosoctavistas-colaboracionistas con Franco y regencialistas-falcondistas-javieristas, nacionalistas moderados frente a radicales en la democracia de 1978.

Entre los lugares de memoria y la topolatría de Navarra, el nacionalismo radical invoca a Roncesvalles (778) y las batallas de Noáin-Salinas y Amayur-Maya (1521-1522), lugares de las derrotas por el ejército castellano-navarro-beamontés del ejército francés-navarro-agramontés, fracasando el intento de recuperar el Reino para Enrique II de Navarra ${ }^{58}$.

El monumento a los fueros de Pamplona tiene signnificado como lugar de la memoria, que utilizan como referente tanto los navarristas como los nacionalistas. Erigido con motivo de la Gamazada (1893-1894) en defensa de la autonomía tributaria para mantener una fiscalidad propia basada en el consumo.

El castillo de Javier tiene distintos significados por ser el lugar de nacimiento del patrón de Navarra y solar de una familia agramontesa, que sufrió la destrucción de su castillo como castigo a los rebeldes, posteriormente amnistiados. También como lugar institucionalizado como centro del catolicismo misionero, que se trató de vincular a la «cruzada» con que se justificó la guerra civil ${ }^{59}$.

El santuario de San Miguel in Excelsis de Aralar lo adquirió desde que el PNV lo declaró patrón del País Vasco y los nacionalistas hicieron de la celebración del Corpus Christi una concentración.

${ }^{56}$ En el documento de HB «Un escenario para la paz en Euskal Herria», 2002, se fundaba el «conflicto político en la actualidad» en «las consecuencias represivas de la Revolución Francesa, las matxinadas, las sucesivas guerras carlistas, las dos guerras mundiales, el alzamiento fascista del año 1936, las luchas obreras y populares contra la dictadura franquista». Monzón, 1982, pp. 35-36, identificó a Zumalacárregui, el cura Santa Cruz, Aguirre y ETA como partícipes en «una misma guerra. Guerra cuyo origen está en que nos robaron la soberanía de nuestro pueblo».

${ }^{57}$ Elorza, 1995, p. 49.

${ }^{58}$ García-Sanz Marcotegui, Iriarte López y Mikelarena Peña, 2002, pp. 117-121; Sánchez Prieto y Olábarri Gortazar, 1985, pp. 1309-1328.

${ }^{59}$ Leoné, 2000, pp. 77-112. 
En Ayeguii, Montejurra es la «montaña saǵrada del carlismo», luǵar vinculado al triunfo militar en la tercera guerra y a los tercios de requetés en la «cruzada», lugar de concentración anual.

El régimen franquista celebró durante cuarenta años el triunfo militar exaltando la memoria y los lugares de sus héroes, mártires o «caídos». A pesar del tiempo transcurrido, la guerra civil es uno de los hechos históricos que siguen utilizándose en el conflicto político por su proximidad histórica, personal y política. La memoria histórica fue objeto de la Ley 52/2007, de 26 de diciembre, por la que se reconocieron y ampliaron derechos y medidas a favor de quienes padecieron persecución o violencia durante la guerra civil y la dictadura. En Navarra el Parlamento el 28 de marzo de 2003 se pronunció sobre el recuerdo, reconocimiento y reparación moral de las personas fusiladas y represaliadas durante la guerra civil en Navarra. Lo hizo la LF 33/2013, de 20 de noviembre, de reconocimiento y reparación moral de las ciudadanas y ciudadanos navarros asesinados y víctimas de la represión a raíz del golpe militar de 1936. La LF 29/2018, de 26 de diciembre, de lugares de memoria histórica de Navarra. Las medidas de recuperación de restos de fosas comunes, la celebración de actos, la construcción de monumentos y la historización de los hechos han generado nuevos lugares de memoria.

El lugar de memoria de los triunfadores en la guerra civil es el monumento a los «muertos en la Cruzada» de Pamplona, en el que estuvieron enterrados los generales golpistas Mola y Sanjurjo, con las inscripciones de los «caídos» franquistas ${ }^{60}$.

La resignificación de este tipo de lugares es una opción utilizada en algunos países, convirtiéndolos en centros de interpretación histórica de acontecimientos históricos o de valores que fueron olvidados en el pasado que aquellos representan, como el campo de concentración de Auschwitz, villa Grimaldi en Peñoa de Santiago de Chile, la casa del terror fascista y comunista de Budapest, la Escuela de Mecánica de la Armada de Buenos Aires y la cárcel política de Lisboa convertida en el Museo de Aljube de la Resistencia y la libertad. Estas experiencias ofrecen soluciones al presente siempre que haya conciencia y voluntad de adoptarlas.

${ }^{60}$ El proceso para su resignnificación se inició con la exhumación de los restos de ambos militares, aunque no se ha loǵrado plenamente, está pendiente de una decisión final sobre el nuevo destino. Tras la guerra civil, desde el 10 de marzo de 1940, era lugar de culto por excombatientes requetés de la Hermandad de Caballeros Voluntarios de la Cruz. La misma organizó la primera «javierada», que la diócesis la resignnificó en acto puramente reliǵioso y misional, como «marcha de la juventud navarra a Javier durante la novena de la gracia». 


\section{Conclusiones}

El uso político de la historia alcanza a la memoria histórica y los lugares de memoria por su conceptualización y representación interesada y utilitaria. Sobre estos se escenifican diversas narrativas, buscando una comunidad de destino entre el presente y el pasado, para aplicarlo a los debates políticos actuales. Se convierten en metarrelatos para confrontar intereses políticos e ideológicos.

En Navarra la construcción de la memoria histórica y de los lugares de memoria ha sido objeto de diversos tratamientos. Hasta el siǵlo XIX se produjo dentro del espacio institucional de la monarquía para encuadrar adecuadamente el «Reino de por sí», su diferenciación y poder propio frente al absolutismo, invocando el pacto de unión, que era el «fuero» del Reino.

El paradiǵma de la revolución liberal obligó a las instituciones navarras a buscar un nuevo modo de acomodación en el sistema político. Se intentó en el momento constituyente de Cádiz. Tras el fracaso de la propuesta, hubo que acordar la salvedad de porciones del poder del Reino dentro de la unidad constitucional, que se realizó por las leyes de 1839 y 1841. Desaparecieron los anteriores «Fueros» para dar lugar a los económico-administrativos propios del régimen liberal.

En el siglo Xx la presencia del nacionalismo y el proceso estatutario vascos durante la II República abrieron el debate doctrinario sobre la identidad de Navarra, la búsqueda del ser y la diferenciación histórica, que justificasen la negativa política a participar en un estatuto e instituciones comunes. Se pasó del debate sobre el alcance del poder institucional concreto anterior al de las abstracciones y la metafísica del ente Navarra y de los fueros como lugar de memoria.

En ese momento se sentaron las bases del navarrismo esencialista e identitario que se recuperó en el tardofranquismo y la Constitución de 1978, con la diferencia de que ahora el conflicto no estaba entre conservadores navarristas y nacionalistas, sino que toda la izquierda asumía la identidad vasca y la integración en el proyecto político de Euskadi. Aquella reconoció los «derechos históricos» susceptibles de concreción en su marco y el de los estatutos de autonomía. La Ley orgánica 13/1982, de la Comunidad Foral, los concretó en facultades y competencias de autogobierno. Los principales lugares de memoria del navarrismo se recogieron en el preámbulo, en un ejemplo de uso político de la historia, que supuso su reconocimiento y proclamación con el máximo rango legal estatal, que nunca había tenido.

\section{Bibliografía}

Alli Aranguren, Juan-Cruz, «Del régimen foral liberal al régimen democrático de los derechos históricos», Revista Jurídica de Navarra, 25, 1998, pp. 51-149. 
Alli Aranguren, Juan-Cruz, «Las instituciones del Reino de Navarra en el primer constitucionalismo español (1808-1814). Navarra en el debate sobre la 'constitución histórica' española», Iura Vasconiae, 8, 2011, pp. 305-384.

Alli Aranguren, Juan-Cruz, «Navarra en el debate constitucional de Cádiz», Revista Jurídica de Navarra, 57, 2012, pp. 107-187.

Alli Aranguren, Juan-Cruz, «Elementos identitarios en el preámbulo y Título Preliminar de la Ley Orgánica 13/1982, de 10 de agosto, de Reintegración y Amejoramiento del Régimen Foral de Navarra», Iura Vasconiae, 11, 2014, pp. 533-573.

Aróstegui, Julio, «Tiempo contemporáneo y tiempo presente. Una reconsideración necesaria», en Marío P. Díaz Barrado, Historia del tiempo presente. Teoría y metodología, Cáceres, Universidad de Extremadura, Instituto Ciencias Educación, Seminario de Historia del Tiempo Presente, 1998, pp. 31-45.

Assmann, Jan, Religión y memoria cultural. Diez estudios, Buenos Aires, Lilmod, 2008.

Baraibar Etxeberria, Álvaro, Extraño federalismo. La vía navarra a la democracia (1973-1982), Madrid, Centro de Estudios Políticos y Constitucionales, 2004

Baraibar Etxeberria, Álvaro, "Tradición e invención en los discursos de la identidad: la democratización de los símbolos de Navarra», en Congréso La Transició de la dictadura franquista a la democracia, Barcelona, Universitat Autónoma de Barcelona, 2005, pp. 529-538.

Baraibar Etxeberria, Álvaro, «Historia y memoria en los discursos en torno a los símbolos de Navarra a lo largo del siǵlo XX», en Navarra: Memoria e Imagen. Actas del VI Congreso de Historia de Navarra, Pamplona, Eunate, 2006, II, pp. 39-50.

Benjamin, Walter, Libro de los pasajes, Madrid, Akal, 2005a.

Benjamin, Walter, Tesis sobre la historia y otros fragmentos, VI, edición y traducción de B. Echeverría, México, edición Contrahistorias, 2005b, www.bolivare.unam.mx/ traducciones [consultado el 28 de septiembre de 2020].

Billig, Michael, Nacionalismo banal, Madrid, Capitán Swing, 2014 [1995].

Billig, Michael, «El nacionalismo banal y la reproducción de la identidad nacional», Revista Mexicana de Sociología, 60, 1, 1998, pp. 37-57.

Burke, Peter, Formas de historia cultural, Madrid, Alianza, 2011.

Chartier, Roger, Sociedad y escritura en la Edad Moderna: la cultura como apropiación, México DF, Instituto Mora, 1995.

Duso, Giuseppe, «Historia conceptual como filosofía política», Res Publica, 1, 1998, pp. 35-71.

Elorza, Antonio, La religión política. El nacionalismo sabiniano y otros ensayos sobre nacionalismo e integrismo, San Sebastián, R \& B, 1995.

Gallerano, Nicola, L'uso pubblico della storia, Milán, Franco Angeli, 1995.

Gallerano, Nicola, «Historia y uso público de la historia», Pasajes: Revista de pensamiento contemporáneo, 24, 2007, pp. 87-97.

García-Sanz Marcotegui, Ángel, Iñaki Iriarte López y Fernando Mikelarena Peña, Historia del navarrismo (1841-1936), sus relaciones con el vasquismo, Pamplona, Universidad Pública de Navarra, 2002.

Habermas, Jürgen, Identidades nacionales y postnacionales, Madrid, Tecnos, 1989,

Halbwachs, Maurice, La memoria colectiva, Zaragoza, Prensas Universitarias de Zaragoza, 2004. 
Hartog, François, y Jacques Revel, Les usages politiques du passé, París, Les Éditions de l'École des Hautes Études en Sciences Sociales, 2001.

Hartog, François, Regímenes de historicidad. Presentismo y experiencias del tiempo, México, Universidad Iberoamericana, 2007.

Hobsbawm, Eric, Naciones y nacionalismo desde 1780, Barcelona, Crítica, 1992.

Hobsbawm, Eric, «Etnicidad y nacionalismo en la Europa de hoy», Inguruak, 19, 1997, pp. 71-72.

Hobsbawm, Eric, Sobre la Historia, Barcelona, Crítica, 1998.

Hobsbawm, Eric, «Introducción: La invención de la tradición», en Eric Hobsbawm y Terence Ranger (eds.), La invención de la tradición, Barcelona, Crítica, 2002.

Huici Miranda, Ambrosio, Estudio sobre la campaña de las Navas de Tolosa, Pamplona, Pamiela, 2011.

Iriarte López, Iñaki, Tramas de identidad. Literatura y regionalismo en Navarra (18701960), Madrid, Biblioteca Nueva, 2000.

Kocka, Jürgen, Historia social y conciencia histórica, Madrid, Marcial Pons, 2002.

Koselleck, Reinhart, Futuro pasado. Para una semántica de los tiempos históricos, Barcelona, Paidós, 1993.

Koselleck, Reinhart, «Historia de los conceptos y conceptos de historia», Ayer, 53, 2004, pp. 27-45.

Koselleck, Reinhart, «Un texto fundamental de Reinhart Koselleck: la introducción al Diccionario de Conceptos Político-Sociales Básicos en lengua alemana, seguida del prólogo de dicha obra», Anthropos, 223, 2009, pp. 6-10.

Lavabre, Marie Claire, «Sociología de la memoria y acontecimientos traumáticos», en Julio Aróstegui y François Godicheau (eds.), Guerra Civil. Mito y memoria, Madrid, Marcial Pons, 2006, pp. 31-55.

Le Goff, Jacques, El orden de la memoria. El tiempo como imaginario, Barcelona, Paidós, 1991.

Leoné Puncel, Santiago, «¿Cómo escribir la identidad de Navarra? De la historia a la metahistoria», Gerónimo de Uztariz, 14-15, 1999a, pp. 9-17.

Leoné Puncel, Santiago, «Entre lo mítico y la nostalgiia», Memoria y civilización: anuario de historia, 2, 1999b, pp. 339-348.

Leoné Puncel, Santiago, «La construcción de San Francisco Javier (1880-1942)», Sancho el Sabio, 13, 2000, pp. 77-112.

Leoné Puncel, Santiago, Los Fueros de Navarra como lugar de la memoria, San Sebastián, FEDHAV, 2005.

Lowenthal, David, El pasado es un país extraño, Madrid, Akal, 1998.

Martín Duque, Ángel (dir.), Signos de identidad histórica de Navarra, Pamplona, Caja de Ahorros de Navarra, 1996.

Monzón, Telesforo de, Hitzak eta idatziak. Herri baten ohiua, Estella, Herri Batasunako Mahai Nazionala, 1982.

Mudroveic, María Inés, Historia, narración y memoria. Los debates actuales en filosofía de la Historia, Madrid, Akal, 2005.

Nancy, Jean-Luc, La Comunidad Inoperante, Santiago de Chile, Escuela de Filosofía Universidad Arcis, 2000.

Nora, Pierre, Les lieux de mémoire, tomo II, París, Gallimard, 1984.

Nora, Pierre, «La aventura de Les lieux de mémoire», Ayer, 32, 1998. 
Nora, Pierre, Pierre Nora en Les Lieux de mémoire, Montevideo, Trilce, 2008.

Pasamar Alzuría, Gonzalo V., «Los historiadores y el uso público de la historia: viejo problema y desafío reciente», Ayer, 49, 2003, pp. 221-248.

Popper, Karl, The Poverty of Historicism, Londres, Routlege and Kegan Paul, 1957.

Ramos, Ramón, «Maurice Halbawchs y la memoria colectiva», Revista de Occidente, 100, 1989, pp. 63-81.

Samuel, Raphael, Theatres of Memory, I. Past and Present in Contemporary Culture, London-New York, Verso, 1999.

Sánchez Prieto, Juan María, «El ser de Navarra entre la historia y la política», en Tercer Congreso General de Historia de Navarra (20 al 23 de septiembre de 1994), Pamplona, Gobierno de Navarra, 1998.

Sánchez Prieto, Juan María, «Prólogo», en Santiago Leoné Puncel, Los Fueros de Navarra como lugar de la memoria, San Sebastián, FEDHAV, 2005, pp. 11-17.

Sánchez Prieto, Juan María, «La construcción simbólica de los Fueros de Navarra», Historia Contemporánea, 47, 2013, pp. 437-470.

Sánchez Prieto, Juan María, y José Luis Nieva, «La aventura política e intelectual de Yanguas y Miranda», Cuadernos del Marqués de San Adrián, 1, 2002, pp. 11-40.

Sánchez Prieto, Juan María, e Ignacio Olábarri Gortazar, «Un ejemplo de 'Richtungskampf' en la historiografía navarra contemporánea. La política en torno a 'Amayur' (1921-1931)», en Symbolae Ludovico Mitxelena septuagenario oblatae, Vitoria, UPV, 1985, vol. 2, pp. 1309-1328.

Supelano-Gross, Claudia, «Entre la esperanza y el recuerdo: aproximación a la filosofía de la historia de Reinhart Koselleck», El Futuro del Pasado, 1, 2010, pp. 53-64.

Traverso, Enzo, El pasado, instrucciones de uso. Historia, memoria, política, Madrid, Marcial Pons, 2007.

Tuan, Yi-Fu, Topofilia, Madrid, Melusinia, 2007.

Wallerstein, Immanuel M., El moderno sistema mundial, I, México, Siglo XXI, 1999.

Yerushalmi, Yosef Hayim, Usos del olvido, Buenos Aires, Nueva visión, 1998. 